\title{
Early-life Socioeconomic Position and the Accumulation of Health-related Deficits by Midlife in the 1958 British Birth Cohort Study
}

Nina T. Rogers, Joanna M. Blodgett, Samuel D. Searle, Rachel Cooper, Daniel H. J. Davis, and Snehal M. Pinto Pereira

Correspondence to: Dr Snehal Pinto Pereira, Institute of Sport, Exercise and Health, Division of Surgery \& Interventional Science, Faculty of Medical Sciences, University College London, London, United Kingdom. (email: snehal.pereira@ucl.ac.uk, Tel: 0207679 5052, Fax: N/A)

For editorial queries contact: Dr Nina Rogers, Institute of Sport, Exercise and Health, Division of Surgery \& Interventional Science, Faculty of Medical Sciences, University College London, London, United Kingdom. (email: n.rogers@ ucl.ac.uk, Tel: 0207679 5052, Fax: N/A)

Author affiliations: Institute of Sport, Exercise and Health, Division of Surgery \& Interventional Science, Faculty of Medical Sciences, University College London, London, United Kingdom (Nina T. Rogers, and Snehal M. Pinto Pereira); MRC Unit for Lifelong Health and Ageing at UCL, 1-19 Torrington Place, London, United Kingdom (Joanna M. Blodgett and Daniel H. J. Davis); Department of Medicine (Geriatrics), Dalhousie University, Halifax, Canada (Samuel D. Searle); Department of Sport and Exercise Sciences, Musculoskeletal Science and Sports Medicine Research Centre, Manchester Metropolitan University, Manchester, United Kingdom (Rachel Cooper)

Funding: This work was supported by a UK Medical Research Council Career Development Award (ref: MR/P020372/1) to SMPP. The views expressed in the publication are those of the authors and not necessarily those of the funders. The funders had no input into study design; data collection, analysis, and interpretation; in the writing of the report; and in the decision to submit the article for publication.

\section{Conflict of interest: None declared}

Running head: Child Socioeconomic position and midlife frailty

(C) The Author(s) 2021. Published by Oxford University Press on behalf of the Johns Hopkins Bloomberg School of Public Health. This is an Open Access article distributed under the terms of the Creative Commons Attribution License (http://creativecommons.org/licenses/by/4.0), which permits unrestricted reuse, distribution, and reproduction in any medium, provided the original work is properly cited. 


\section{ABSTRACT}

Reducing population levels of frailty is an important goal and preventing its development in midadulthood could be pivotal. There is limited evidence on associations between childhood socioeconomic position (SEP) and frailty. Using 1958 British birth cohort data (followed from 1958 to 2016; $\mathrm{N}=8711$ ), we aimed to: (i) establish the utility of measuring frailty in mid-life, by examining associations between a 34 -item frailty index at 50y $\left(\mathrm{FI}_{50 \mathrm{y}}\right)$ and mortality $(50-58 \mathrm{y})$ and, (ii) examine associations between early-life SEP and $\mathrm{FI}_{50 \mathrm{y}}$, and investigate whether these associations were explained by adult SEP. Hazard ratios (HRs) for mortality increased with increasing frailty, e.g., $\mathrm{HR}_{\text {sex-adjusted }}$ was 4.07(95\% CI:2.64,6.25) for highest vs. lowest fifth of FI 5 \%y. Lower early-life SEP was associated with higher $\mathrm{FI}_{50 \mathrm{y}}$. Compared with participants born in the highest social class, the estimated total effect on $\mathrm{FI}_{50 \mathrm{y}}$ was $42.0 \%(35.5 \%, 48.4 \%$ ) for participants born in the lowest class, with the proportion mediated by adult SEP being $0.45(0.35,0.55)$. Mediation by adult SEP was negligible, for other early-life SEP classes. Findings suggest that early-life SEP is associated with frailty and that adult SEP only partially explains this association. Results highlight the importance of improving socioeconomic circumstances across the life course to reduce inequalities in mid-life frailty.

Keywords: Birth cohort, childhood circumstances, early-life socioeconomic position, frailty, healthy ageing, life course

Abbreviations: FI (Frailty Index); $\mathrm{FI}_{50 \mathrm{y}}$ (Frailty Index at 50 years); SEP (socioeconomic position) 
Frailty, a state of increased vulnerability as a consequence of age-related decline in physiological reserves(1), is associated with adverse health outcomes including falls, hospitalisations and premature mortality $(1,2)$. While there is no universal consensus regarding the operationalization of frailty(3), the two most common approaches define frailty as a phenotype(4) (based on five pre-defined physical frailty criteria(5)), or a frailty index (FI), based on an accumulation of health-related deficits(6,7). Despite lack of a standard definition, there is acknowledgement that frailty presents a global challenge because of population ageing $(8,9)$. Although prevalence of frailty increases with age, it is not limited to older ages(10). Yet, most epidemiological studies assessing predictors of frailty have focused exclusively on adults aged 65 and over(11-13). This omission is importánt because frailty reflects biological rather than chronological age(14) and is a dynamic process that may be reversible(15). However, increasing age (65y onwards) is associated with a lower probability of improvement in frailty status(16). Thus, there is emerging recognition that attention to frailty in midadulthood could be pivotal in terms of identifying, managing, and preventing severe frailty at older $\operatorname{ages}(17,18)$.

Reducing frailty at the population level is a desirable goal. To achieve this, a more precise understanding of predictors of frailty from mid-life onwards is key to delaying its onset. A life course approach to frailty has been discussed theoretically $(19,20)$, and has the potential to identify when and how to intervene at different life-stages to maximize the chance of healthy population aging(19). However, to date only few empirical life course studies examine frailty. For example, a literature is emerging on links betweén early-life socioeconomic position (SEP) and frailty at older ages(13,2125). However, thesé studies have relied on relatively small sample sizes $(\mathrm{N}<1,100)(13,25)$ and retrospective reports of early-life $\operatorname{SEP}(21,22)$. Importantly, previous studies have examined mainly older adults and where younger adults have been considered(21,23-25), the age range has been broad, with little consideration for age-related differences in associations. While associations between frailty in adulthood and mortality are well established(1), evidence suggests that frailty levels may have increased in recent generations(26). In addition, some(27), but not all(28), studies suggest that the strength of the frailty-mortality association may have weakened in more recent generations. 
Thus, there is utility in examining frailty associations with both mortality and upstream factors, such as early-life SEP, in a single-aged sample from mid-adulthood to help clarify when in the life course these associations emerge.

Despite the burgeoning literature linking early-life SEP to frailty, only a few studies $(13,24,25)$

examine whether this association is due to life course continuities in disadvantage. Limited evidence suggests that adult socioeconomic circumstances fully explain associations between early-life SEP and frailty at older ages $(13,24,25)$. However, these studies have several methodological limitations. For example, using a single indicator of adult SEP, such as occupational class(13,25), may result in mismeasurement of the mediator, potentially undermining the analysis(29). Moreover, confounders of the adult SEP - frailty relationship, such as smoking(30,31), that are themselves influenced by early-life SEP(32), were not accounted for. No study has examined these chains of associations in mid-life, and almost all operationalize frailty as a phenotype(13,21,23-25) with few using a FI(22). The validated FI(6) is particularly suitable for examining frailty in mid-adulthood because, compared with other frailty measures (including the frailty phenotype), it is more sensitive to small changes in health status(33) making it particularly suitable for examining frailty in mid-adulthood, a life-stage when health deficits are accumulating at a slower rate than at older ages(34).

We aim to address several outstanding research gaps regarding the utility of measuring frailty in midlife and the links between early-life SEP and frailty. Specifically, using data from the 1958 British Birth Cohort, we derived a FI at 50y (referred to $\mathrm{FI}_{50 \mathrm{y}}$ ). To provide construct validity and establish the utility of measuring frailty in mid-life, we examined associations between $\mathrm{FI}_{50 \mathrm{y}}$ and mortality over an eight-year follow-up period. We then examined associations between early-life SEP and $\mathrm{FI}_{50 \mathrm{y}}$ and investigated whether these associations were explained by adult SEP.

\section{METHODS}

The 1958 British Birth Cohort includes over 17,000 participants followed-up since birth during a single week in March 1958(35). Ethical approval was given, including at 50y by the London multi- 
centre Research Ethics Committee and participants gave informed consent at various ages.

Respondents in mid-adulthood are broadly representative of the surviving cohort(36). At 50y, 9,789 individuals participated, of these 8,711 had a valid measure of $\mathrm{FI}_{50 \mathrm{y}}$ (Figure $\mathrm{S} 1$ ) and were included in the analysis. Compared to cohort members who took part at 50y, but had insufficient information to create a FI $(\mathrm{N}=1,078)$, participants included in this study had a more favorable SEP in early-life and in adulthood (Web Table 1).

The frailty index: was derived following guidelines(37). Included variables met the following criteria: a) a health-associated deficit with a prevalence that generally increases with age, b) not universal in the adult population by midlife (e.g. myopia is not included but age-related sight changes (presbyopia) is included); and c) when taken together the included variables cover a range of physiological systems and processes. The $\mathrm{FI}_{50 \mathrm{y}}$ included 34 variables (Table 1) covering eight broad health domains (comorbidities, physical functioning, sensory functioning, mental health, cognitive function, fatigue, sleep and general health). Most variables were dichotomised and given a score of 1 (deficit present) or 0 (deficit absent). Following guidelines(37), individuals (N=8,711; 89.0\%) were included provided they had information on at least 30 deficits. For each included individual, $\mathrm{FI}_{50 \mathrm{y}}$ was generated by summing the total number of deficits reported and dividing by the total number of deficits considered (i.e. number of considered deficits varied from 30 to 34), giving a continuous score between 0 and 1.

Mortality: Information on deaths from 2008 (when cohort members were 50y) to the end of 2016 (when cohort members were 58y) was ascertained from a variety of sources, the majority (94.7\%; n=198) through linkage to death certificates from the National Health Service Central Register(38). Information from relatives or close friends during survey activities/cohort maintenance allowed identification of 11 further deaths (Web Table 2 footnotes). 
Early-life Socioeconomic Position: was identified from prospectively recorded information on father's occupation at birth in 1958 or if missing at 7y in $1965(\mathrm{n}=631(7.24 \%))$. Using the Registrar General's Social Classification groupings, four categories were identified: professional/managerial (classes I/II), skilled non-manual (class III non-manual), skilled manual (class III manual) and partly skilled/unskilled manual (classes IV/V and cases where there was no male household head).

Adult Socioeconomic Position: was considered a potential intermediary based on established associations with both early-life $\operatorname{SEP}(39,40)$ and frailty $(26,41)$. It was represented by occupational class at $42 \mathrm{y}$ (or if missing at $33 \mathrm{y}(\mathrm{n}=829(9.52 \%))$, educational attainment by $33 \mathrm{y}$, and household tenure at $45 \mathrm{y}$ (see Table 2 footnotes).

Confounders: were identified a-priori, based on factors associated with early-life SEP, adult SEP and frailty. These included sex as a baseline confounder and physicalactivity $(42,43), \operatorname{smoking}(30,31)$ and problem drinking $(30,44)$ as confounders of the adult SEP - frailty relationship that are influenced by early-life SEP(32,43,45) (see Figure 1 and Web Appendix1).

Statistical analysis:

Proportional hazards for mortality were visually assessed using Kaplan-Meier plots. Cox proportional hazard models (sex-adjusted) estimated hazard ratios and 95\% confidence intervals (HR(95\%CI)) of associations between the $\mathrm{FI}_{50 \mathrm{y}}$ and all-cause mortality between ages $50 \mathrm{y}-58 \mathrm{y}$. Associations between FI and mortality are commonly examined using a continuous measure(46) or pre-specified FI categories (e.g. $0-0.1,0.1-0.2$, etc) $(2,47,48)$. In mid-life, the FI is highly skewed (e.g. $\sim 60 \%$ of the sample have a FI<0.1), thus, these categorizations are not appropriate. Therefore, similar to others, We divided $\mathrm{FI}_{50 \mathrm{y}}$ into fifths(49). Survival time included time from completion of the 50y survey to date of death, censoring (last date of contact) or end of the study period (December 2016), whichever came first. Schoenfeld residuals were checked to test the assumption of proportional hazards for $\mathrm{FI}_{50 \mathrm{y}}$ and sex; neither violated the assumption. 
Using linear regression, we examined whether associations between early-life SEP and $\mathrm{FI}_{50 \mathrm{y}}$ varied by sex; there was no evidence of effect modification $(P=0.35)$, hence sex-adjusted analyses are presented. For ease of interpretation, $\mathrm{FI}_{50 \mathrm{y}}$ was log-transformed and multiplied by 100 , whereby regression coefficients can be interpreted as the symmetric percentage difference in means(50). Before log-transforming $\mathrm{FI}_{50 \mathrm{y}}$, we added 0.01 to the index, as in previous work(51), to circumvent logarithm values of zero.

\section{Creation of latent classes to represent adult SEP}

To account for potential measurement error introduced by using a single indicator of adult SEP, a latent class variable was created using adult occupational class, educational attainment and household tenure, that capture different aspects of $\operatorname{SEP}(52)$. The best fitting clas solution was based on model fit statistics: the Akaike(53) and Bayesian (54) information criterion, with lower values indicating better fit. Class discrimination was assessed using entropy, with values of 0.6 or higher indicating good class separation(55). After identifying the optimal number of classes, individuals were assigned to their most likely class, creating a categorical variable to represent adult SEP that was used in subsequent analyses.

\section{Mediation analysis}

Details of the adopted counterfactual approach are given elsewhere(56). In brief, we compare scenarios whereby the entire population is assigned a specific category for early-life SEP (i.e. classes I/II (baseline), class III non-manual, class III manual or classes IV/V) and adult SEP (represented by a latent variable). Our targets of estimation, the total effect (TE), natural direct effect (NDE) and natural indirect effect (NIE) are estimated for each of the three levels of early-life SEP compared to the baseline (classes I/II). For each level of early-life SEP, the TE on frailty is partitioned into the effect mediated via adult SEP (NIE) and a non-mediated effect (NDE).

For each level of early-life SEP compared to the baseline, the TE is the percent difference in frailty comparing two situations: the percent difference in mean $\mathrm{FI}_{50 \mathrm{y}}$ if all individuals were assigned to (i) the level of early-life SEP under consideration and (ii) the baseline category of early-life SEP. For 
each level of early-life SEP compared to the baseline, the NDE is the percent difference in frailty comparing the situation where all individuals are assigned to early-life SEP at (i) the level under consideration and adult SEP at the value that would have been observed when early-life SEP is set at its baseline and (ii) the baseline level (with adult SEP set to the value that would be observed when early-life SEP is set at its baseline level). The NIE is the difference between the relevant TE and NDE. We estimated these effects using the g-computation procedure in STATA version 15 (StataCorp, LP, College Station, Texas) (56) (see Web Appendix 2). This procedure allows us to estimate the effects of interest allowing for confounders between adult SEP and frailty that are influenced by early-life SEP.

We conducted sensitivity analysis to determine whether any single item or one of the eight domains in the FI was particularly important for examined relationships. We systematically removed one item (or domain) at a time from the FI and examined associations between (i) $\mathrm{FI}_{50 \mathrm{y}}$ (minus the single item/domain) and subsequent mortality and (ii) early-life SEP and $\mathrm{FI}_{50 \mathrm{y}}$ (minus the single item/domain).

Missing data ranged from $2.80 \%$ (early-life SEP) to $21.0 \%$ (45y problem drinking). To minimize data loss, missing information for confounders, early-life and adult SEP were imputed using chained equations. Following guidelines(57), imputation models included all substantive variables and main predictors of missingness (childhood internalizing and externalizing behaviours and cognitive ability)(36). Linear regressions were run across 20 imputed datasets; overall estimates were obtained. For the g-computation procedure, a single imputation was used (bootstrapped standard errors were used to calculate $95 \%$ confidence intervals).

\section{RESULTS}

As expected, the $\mathrm{FI}_{50 \mathrm{y}}$ was right skewed, with a median of 0.07 for both males and females, corresponding to an expression of approximately $2(34 * 0.07)$ health-related deficits (Table 2$)$. While 
$20 \%$ of the cohort had fathers in the highest occupational classes (I/II) when they were born, $42 \%$ were themselves in this occupational class at $42 \mathrm{y}$.

Associations between early-life SEP, $F_{50 y}$ and mortality

Sex-adjusted Kaplan-Meier curves indicated that mortality generally increased progressively with increasing levels of frailty (Figure 2). For example, compared to the least frail adults, the $\mathrm{HR}_{\text {sex-adjusted }}$ was $1.66(1.01,2.74)$ for adults in the fourth highest frailty fifth and 4.07(2.64,6.25) for the most frail adults (Web Table 2). Associations between the FI and mortality remained stable when we systematically excluded a single item or domain from the FI. For example, per increase in frailty fifth, the $\mathrm{HR}_{\text {sex-adjusted }}$ for mortality was $1.48(1.32,1.67)$; removing a single item from the index resulted in HRs ranging from 1.40(1.28,1.54) to 1.54(1.38,1.71) when "self-reported health" and "number of animals named in 1 minute" were removed respectively. When the domains were removed, HRs ranged from 1.38(1.24,1.54) for cognitive function to $1.50(1.33,1.69)$ for comorbidities (Figure S2a).

Lower early-life SEP was associated with greater percentage differences in $\mathrm{FI}_{50 \mathrm{y}}$. For example, each decrease (on a 4-point scale) in early-lífe SEP, was associated with a 14.2\%(12.1\%,16.3\%)increase in FI. Associations between earlyzlife SEP and FI were broadly stable when a single item or domain was removed from the FI. For example, percent increases in FI ranged from $11.2 \%(9.48 \%, 13.1 \%)$ to $14.8 \%(12.7 \%, 16.9 \%)$ when "self-reported health" and "expect health to get worse" were removed, respectively. Associations ranged from $14.2 \%(12.1 \%, 16.4 \%)$ to $10.2 \%(7.56 \%, 12.5 \%)$ when domains sensory functioning and cognitive function were respectively removed (Figure S2b).

Latent classes to represent adult SEP

Two to five latent classes were considered. The four-class solution was our chosen solution, because it had the smallest AIC and BIC and a satisfactory entropy score (Web Table 3). The predicted probability of adult occupational class, education and tenure in each of the four latent classes is shown in Web Table 4. 


\section{Mediation analysis}

The estimated total effect of early-life SEP on $\mathrm{FI}_{50 \mathrm{y}}$ was $10.3 \%(3.02 \%, 17.7 \%)$ for participants with fathers in III non-manual, $27.8 \%(22.2 \%, 33.3 \%)$ for III manual and 42.0\%(35.5\%,48.4\%) for IV/V when compared to participants with fathers in class I/II (Table 3). When partitioned, compared to participants with fathers in class I/II, the estimated natural direct effect of participants with fathers in III non-manual, III manual and IV/V was $15.3 \%(7.88 \%, 22.7 \%), 32.4 \%(26.6 \%, 38.1 \%)$ and $23.0 \%$ $(16.4 \%, 29.7 \%)$ respectively. Mediation by (the latent variable representing) adult SEP was negligible, except for participants with fathers in IV/V, where the proportion mediated was $0.45(0.35,0.55)$.

\section{DISCUSSION}

Our study examining early-life SEP in relation to the accumulation of health-related deficits by midadulthood, in a general population sample, is important for several reasons. First, we show that by mid-life, health deficits have begun to accumulate. For example, a median FI of 0.07 indicates that half the population at 50y had at least two of the considered health deficits and similarly, a quarter of the population had at least four deficits. Second, it was noteworthy that this accumulation of deficits at a relatively young age was strongly associated with mortality up to eight years later. For example, morality hazards were four times higher, comparing adults with the most $(\geq 5)$ to those with the least (0-1) number of deficits. Third, lower SEP in early-life was associated with higher levels of frailty by mid-adulthood, such that the estimated total effect on $\mathrm{FI}_{50 \mathrm{y}}$ for those born in the lowest compared to highest SEP category was $42 \%$ greater. Finally, compared to those born in the highest SEP category, the effect of early-life SEP on frailty for those born in the lowest SEP category only, was partly explained by continuities in disadvantage into adulthood.

A major study strength, over previous work, is the examination of an age-homogenous sample. Age is associated strongly with frailty(7), and this influence can be eliminated in our study. Further strengths include examination of a large general population sample with prospectively collected data from birth, a validated measure of frailty capturing multiple health domains, and accounting for confounders of the adult SEP-frailty relationship. We acknowledge that there is no single best 
indicator of SEP(52). We used father's occupation at birth to represent early-life SEP because it is a commonly used measure, reflecting a wide range of early-life social and economic indicators including the household's educational attainment, income levels and social standing. In addition, rather than using a single measure of SEP in adulthood, we constructed a latent variable capturing three different well-established aspects of adult SEP(52). Health deficits accumulate at a slower rate in mid-life than at older ages(34) and frailty measured in younger populations might be clinically and biologically different from that measured in older populations(1). Nonetheless, our measure of frailty is particularly suited to mid-life because it has demonstrated good construct validity at this lifestage(58) and it provides a continuous score of fitness to frail(6) allowing detection of small differences in health compared to other measures(33). Regarding temporality, our indicators of adult SEP were captured prior to 50y, when the FI was constructed. This provides some evidence supporting the temporal sequence of events, which is further bolstered by evidence from several cohorts showing associations between adult SEP and a range of subsequent health conditions (59). However, we do acknowledge that health can also influence subsequent $\operatorname{SEP}(30)$. Our mediation analysis relies on several assumptions including no unmeasured confounding and accurate parametric modelling; but required assumptions are less stringent than those for conventional alternative analyses. Finally, as with all long-term studies, attrition occurred over time. Although participants in this study had more favourable early-life and adult SEP compared to those not included, in general the sample remains broadly representative of the original cohort(36). Further sample reductions due to missing data were prevented by using imputation.

Our findings that health deficits have already begun to accumulate by 50y and are associated with subsequent mortality agrees with the literature on the accumulation of health deficits in midlife(47,60). Although the implications of frailty in clinical practice may vary by age, we and others $(18,60)$ demonstrate the utility of measuring frailty earlier in the life course. Thus, our findings emphasise that measuring frailty at a particular age is meaningful in identifying individuals at risk of adverse health outcomes and, because frailty is progressive, beginning with a preclinical stage, there are opportunities for early prevention(1). Furthermore, our finding that the early-life SEP-frailty and 
frailty—mortality associations were not largely driven by any single item or health domain suggests that the value of the FI exceeds any single item/domain.

Our results are consistent with previous studies showing that lower early-life SEP is associated with greater risk of frailty in adulthood $(13,24,25)$ such that compared to those born in the highest SEP category, those born in the lowest category had a $42 \%$ higher FI at 50y. However, we found that the estimated effect of early-life SEP on frailty mediated by adult SEP to be noteworthy only for the lowest (compared to the highest) SEP category at birth. Since adult SEP did not fully explain earlylife SEP associations in this cohort, other explanatory pathways may be involved. Evidence suggests that early-life socioeconomic disadvantage may lead to poor adult health via biological embedding(61). For example, abnormal biological changes have been observed in adults who experienced early-life socioeconomic disadvantage in this cohort(62) and elsewhere(63), which have been proposed to lead to accelerated ageing(64). In addition, pathways via obesity and physical activity maybe relevant, and warrant further research. Findings that the estimated direct effects of the two intermediate early-life SEP categories were larger than the corresponding estimated total effects were surprising and in contrast to previous studies where adult SEP fully explained early-life SEP-frailty associations. Discrepancies may be due to the single-aged sample examined here compared with the broad age ranges previously examined $(24,25)$ or the younger age of adults in this study compared to others(13). Notwithstanding this difference, our findings are in agreement with others, that adult SEP is an important intermediary through which early-life disadvantage is associated with mid-life frailty. Therefore, our findings, together with other evidence, suggests that interventions to improve adult socioeconomic circumstances of those from disadvantaged backgrounds may reduce the burden of frailty in mid-life and beyond.

In conclusion, our findings have several practical and policy relevant implications. They emphasize the value of using previously collected health data to identify those who may be vulnerable to accelerated ageing earlier in the life course. Derivations of the FI are widely used in clinical and primary care settings in England(6,65) to systematically identify the extent of frailty in adults aged 65 
and over. Our findings suggest that similar assessments could be valuable in mid-adulthood and suggests that in a primary care setting, in addition to considering single health deficits in mid-life, the accumulation of deficits is also important. Identifying adults in mid-life who could benefit from early interventions might reduce the burden of frailty at older ages, improving quality of life and reducing healthcare costs $(18,60)$. We highlight the importance of improving socioeconomic conditions over the whole life course in order to reduce health inequalities. Thus, a potential intervention focus could be on improving socioeconomic opportunities available in adulthood for those disadvantaged in childhood. Moreover, relative child poverty is projected to rise from $29.7 \%$ to $36.6 \%$ in the UK between 2018 to 2022(66), thus our findings underscore the importance of much needed policies to redress socioeconomic inequalities in childhood because they have the potential to improve health in mid-adult life and beyond.

\section{ACKNOWLEDGEMENTS}

Author affiliations: Institute of Sport, Exercise and Health, Division of Surgery \& Interventional Science, Faculty of Medical Sciences, Uniyersity College London, London, United Kingdom (Nina T. Rogers, and Snehal M. Pinto Pereira); MRC Unit for Lifelong Health and Ageing at UCL, 1-19 Torrington Place, London, United Kingdom (Joanna M. Blodgett and Daniel H. J. Davis); Department of Medicine (Geriatrics), Dalhousie University, Halifax, Canada (Samuel D. Searle); Department of Sport and Exercise Sciences, Musculoskeletal Science and Sports Medicine Research Centre, Manchester Metropolitan University, Manchester, United Kingdom (Rachel Cooper)

Funding: This work was supported by a UK Medical Research Council Career Development Award (ref. MR/P020372/1) to SMPP. The views expressed in the publication are those of the authors and not necessarily those of the funders. The funders had no input into study design; data collection, analysis, and interpretation; in the writing of the report; and in the decision to submit the article for publication. 
Contributors: NTR and SMPP conceived the study and drafted the paper. JB and SS advised on construction of the frailty index at 50y. NTR and SMPP carried out the analysis. All authors contributed to the interpretation of data, revision of the manuscript, and approved its final version.

Data Availability: Cohort data comply with ESRC data sharing policies, readers can access these data via the UK Data Archive at http://www. data- archive.ac.uk/. The authors are grateful to the Centre for Longitudinal Studies (CLS), UCL Institute of Education, for the use of the 1958 cohort data and to the UK Data Service for making them available. However, neither CLS nor the UKĐata Service bear any responsibility for the analysis or interpretation of these data.

Conflicts of interest: None declared

\section{References}

1. Clegg A, Young J, Iliffe S, et al. Frailty in elderly people. Lancet. 2013;381(9868):752-762.

2. Kojima G, Iliffe $S$, Walters K. Frailty index as a predictor of mortality: a systematic review and meta-analysis. Age Ageing. 2018;47(2):193-200.

3. Theou 0, Brothers TD, Mitnitski A, et al. Operationalization of frailty using eight commonly used scales and comparison of their ability to predict all-cause mortality. J. Am. Geriatr. Soc. 2013;61(9):1537-51.

4. Theou O, Walston J, Rockwood K. Operationalizing Frailty Using the Frailty Phenotype and Deficit Accumulation Approaches. Interdiscip. Top. Gerontol. Geriatr. 2015;41:66-73.

5. Fried LP, Tangen CM, Walston J, et al. Frailty in older adults: evidence for a phenotype. J. Gerontol. A Biol Sci Med Sci. 2001;56(3):46-56.

6. Rockwood K, Song X, MacKnight C, et al. A global clinical measure of fitness and frailty in elderly people. CMAJ. 2005;173(5):489-95.

7. Rockwood K, Mitnitski A. Frailty in relation to the accumulation of deficits. J. Gerontol. A. Biol. Sci. Med. Sci. 2007;62(7):722-7.

8. Buckinx F, Rolland Y, Reginster J-Y, et al. Burden of frailty in the elderly population: perspectives for a public health challenge. Arch. Public Heal. 2015;73(1):19.

9. Future of an Ageing population; Government Office for Science. 2016;(https://www.gov.uk/government/publications/future-of-an-ageing-population). (Accessed February 5, 2021)

10. Rockwood K, Blodgett JM, Theou 0, et al. A Frailty Index Based On Deficit Accumulation Quantifies Mortality Risk in Humans and in Mice. Sci. Rep. 2017;7:43068.

11. Ding YY, Kuha J, Murphy M. Multidimensional predictors of physical frailty in older people: identifying how and for whom they exert their effects. Biogerontology. 2017;18(2):237-252.

12. Hajek A, Brettschneider C, Posselt T, et al. Predictors of Frailty in Old Age - Results of a Longitudinal Study. J. Nutr. Health Aging. 2016;20(9):952-957. 
13. Gale CR, Booth T, Starr JM, et al. Intelligence and socioeconomic position in childhood in relation to frailty and cumulative allostatic load in later life: the Lothian Birth Cohort 1936. J. Epidemiol. Community Health. 2016;70(6):576-82.

14. Mitnitski AB, Graham JE, Mogilner AJ, et al. Frailty, fitness and late-life mortality in relation to chronological and biological age. BMC Geriatr. 2002;2:1.

15. Gill TM, Gahbauer EA, Allore HG, et al. Transitions Between Frailty States Among Community-Living Older Persons. Arch. Intern. Med. 2006;166(4):418-423.

16. Lee JSW, Auyeung T-W, Leung J, et al. Transitions in Frailty States Among CommunityLiving Older Adults and Their Associated Factors. J. Am. Med. Dir. Assoc. 2014;15(4):281286.

17. Mitnitski A, Rockwood K. The rate of aging: the rate of deficit accumulation does not change over the adult life span. Biogerontology. 2016;17(1):199-204.

18. Hanlon P, Nicholl BI, Jani BD, et al. Frailty and pre-frailty in middle-aged and older adults and its association with multimorbidity and mortality: a prospective analysis of 493737 UK Biobank participants. Lancet Public Heal. 2018;3(7):e323-e332.

19. Kuh D. A Life Course Approach to Healthy Aging, Frailty, and Capability. Journals Gerontol. Ser. A Biol. Sci. Med. Sci. 2007;62(7):717-721.

20. Bergman H, Ferrucci L, Guralnik J, et al. Frailty: an emerging research and clinical paradigm--issues and controversies. J. Gerontol. A. Biol. Sci. Med. Sci. 2007;62(7):731-7.

21. Alvarado BE, Zunzunegui $\mathrm{M}-\mathrm{V}$, Béland $\mathrm{F}$, et al. Life course social and health conditions linked to frailty in Latin American older men and women. J. Gerontol. A. Biol. Sci. Med. Sci. 2008;63(12):1399-406.

22. Herr M, Robine J-M, Aegerter P, et al. Contribution of socioeconomic position over life to frailty differences in old age: comparison of life-course models in a French sample of 2350 old people. Ann. Epidemiol. 2015;25(9):674-680.

23. Li Y, Xue Q-L, Odden MC, et al. Linking early life risk factors to frailty in old age: evidence from the China Health and Retirement Løngitudinal Study. Age Ageing. 2020;49(2):208217.

24. Van der Linden BWA, Cheval B, Sieber S, et al. Life Course Socioeconomic Conditions and Frailty at Older Ages. Journals Gerontol,Ser. B. 2019;75(6):1348-1357.

25. Haapanen MJ, Perälä MM, Salønen MK, et al. Early life determinants of frailty in old age: the Helsinki Birth Cohort Study. Age Ageing. 2018;47(4):569-575.

26. Marshall A, Nazroo J, Tampubolon G, et al. Cohort differences in the levels and trajectories of frailty among older people in England. J. Epidemiol. Community Health. 2015;69(4):316-321.

27. K Bäckman; E, Joas; H, Falk; A, Mitnitski; K, Rockwood; I S. Changes in the Lethality of Frailty Over 30 Years: Evidence From Two Cohorts of 70-Year-Olds in Gothenburg Sweden. J. Gerontol. A. Biol. Sci. Med. Sci. 2017;72(7):945-950.

28. Mousa A, Savva GM, Mitnitski A, et al. Age and ageing. Age Ageing. 2018;47:721-727.

29. VanderWeele TJ, Valeri L, Ogburn EL. The role of measurement error and misclassification in mediation analysis: mediation and measurement error. Epidemiology. 2012;23(4):561-4.

30. Harrison S, Davies AR, Dickson M, et al. The causal effects of health conditions and risk factors on social and socioeconomic outcomes: Mendelian randomization in UK Biobank. Int. J. Epidemiol. 2020;49(5):1661-1681.

31. Kojima G, Iliffe S, Walters K. Smoking as a predictor of frailty: A systematic review. BMC Geriatr. 2015;15(1):131.

32. Mckenzie SK, Carter KN, Blakely T, et al. Effects of childhood socioeconomic position on subjective health and health behaviours in adulthood: how much is mediated by adult socioeconomic position? BMC Public Health. 2011;11(1):269.

33. Jang I-Y, Jung H-W, Lee HY, et al. Evaluation of Clinically Meaningful Changes in Measures of Frailty. Journals Gerontol. Ser. A. 2020;75(6):1143-1147.

34. Kulminski A, Ukraintseva S V., Akushevich I, et al. Accelerated accumulation of health 
deficits as a characteristic of aging. Exp. Gerontol. 2007;42(10):963-970.

35. Power C, Elliott J. Cohort profile: 1958 British birth cohort (National Child Development Study). Int. J. Epidemiol. 2006;35(1):34-41.

36. Atherton K, Fuller E, Shepherd P, et al. Loss and representativeness in a biomedical survey at age 45 years: 1958 British birth cohort. J. Epidemiol. Community Health. 2008;62(3):216-23.

37. Searle SD, Mitnitski A, Gahbauer EA, et al. A standard procedure for creating a frailty index. BMC Geriatr. 2008;8:24.

38. University of London. Institute of Education. Centre for Longitudinal Studies. National Child Development Study Deaths Dataset, 1958-2016: Special Licence Access. 3rd Editiøn. UK Data Service. SN: 7717.

(https://beta.ukdataservice.ac.uk/datacatalogue/doi/?id=7717\#!\%233). (Accessed June $28,2020)$

39. Hossin MZ, Björk J, Koupil I. Early-life social and health determinants of adult socioeconomic position: associations and trends across generations. J Epidemiol Community Heal. 2020;74(5):412-420.

40. Broer M, Bai Y, Fonseca F. A Review of the Literature on Socioeconomic Status and Educational Achievement. In: Socioeconomic Inequality and Educational Outcomes. IEA Research for Education (A Series of In-depth Analyses Based on Datd of the International Association for the Evaluation of Educational Achievement (IEA)), vol 5. Springer; 2019

41. Hoogendijk EO, van Hout HPJ, Heymans MW, et al. Explaining the association between educational level and frailty in older adults: Results from a 13-year longitudinal study in the Netherlands. Ann. Epidemiol. 2014;24(7):538-44.

42. Rogers NT, Marshall A, Roberts $\mathrm{CH}$, et al. Physical activity and trajectories of frailty among older adults: Evidence from the English Longitudinal Study of Ageing. PLoS One. 2017;12(2).

43. Pinto Pereira SM, Li L, Power C. Early-Life Predictors of Leisure-Time Physical Inactivity in Midadulthood: Findings From a Prospective British Birth Cohort. Am. J. Epidemiol. 2014;180(11):1098-1108.

44. Strandberg AY, Trygg T, Pitkälä $\mathrm{KH}$, et al. Alcohol consumption in midlife and old age and risk of frailty. Age Ageing. 2018;47(2):248-254.

45. Gauffin K, Hemmingsson T, Hjern A. The effect of childhood socioeconomic position on alcohol-related disorders later in life: a Swedish national cohort study. J. Epidemiol. Community Health. 2013;67(11):932-8.

46. Hoogendijk EO, Stenholm S, Ferrucci L, et al. Operationalization of a frailty index among older adults in the InCHIANTI study: predictive ability for all-cause and cardiovascular disease mortality. Aging Clin. Exp. Res. 2020;32(6):1025-1034.

47. Blodgett JM, Theou O, Howlett SE, et al. A frailty index from common clinical and laboratory tests predicts increased risk of death across the life course. GeroScience. 2017,39(4):447-455.

48. Williams DM, Jylhävä J, Pedersen NL, et al. A Frailty Index for UK Biobank Participants. Journals Gerontol. Ser. A. 2019;74(4):582-587.

49. Wong TY, Massa MS, O'Halloran AM, et al. Cardiovascular risk factors and frailty in a cross-sectional study of older people: implications for prevention. Age Ageing. 2018;47(5):714-720.

50. Cole TJ, Altman DG. Statistics Notes: Percentage differences, symmetry, and natural logarithms. BMJ. 2017;358(j3683).

51. Gale CR, Westbury L, Cooper C. Social isolation and loneliness as risk factors for the progression of frailty: the English Longitudinal Study of Ageing. Age Ageing. 2018;47(3):392-397.

52. Galobardes B, Shaw M, Lawlor DA, et al. Indicators of socioeconomic position (part 1). J. Epidemiol. Community Health. 2006;60(1):7-12.

53. Akaike H. Information theory and an extension of the maximum likelihood principle. In: 
Proc. 2nd Int.Symp. information Theory (eds B. N. Petrov and F. Csaki). Budapest; 1973:267-281.

54. Schwarz G. Estimating the Dimension of a Model. Ann. Stat. 1978;6(2):461-464.

55. Asparouhov T, Muthén B. Auxiliary Variables in Mixture Modeling: Three-Step Approaches Using M plus. Struct. Equ. Model. A Multidiscip. J. 2014;21(3):329-341.

56. Daniel RM, De Stavola BL, Cousens SN. Gformula: Estimating Causal Effects in the Presence of Time-Varying Confounding or Mediation using the G-Computation Formula. Stata J. 2011;11(4):479-517.

57. Sterne JAC, White IR, Carlin JB, et al. Multiple imputation for missing data in epidemiological and clinical research: potential and pitfalls. BMJ. 2009;338(b2393).

58. Kanters, DM; Griffith, LE; Hogan, DB, ; Richardson, J; Patterson, C; Raina P. Assessing the Measurement Properties of a Frailty Index Across the Age Spectrum in the Canadian Longitudinal Study on Aging. J. Epidemiol. Community Health. 2017;71(8).

59. Kivimäki M, Batty GD, Pentti J, et al. Association between socioeconomic status and the development of mental and physical health conditions in adulthood: a multi-cohort study. Lancet. Public Heal. 2020;5(3):e140-e149.

60. Pérez-Zepeda MU, Godin J, Armstrong JJ, et al. Frailty among middle-aged and older Canadians: population norms for the frailty index using the Canadian Longitudinal Study on Aging. (Available online ahead of print: doi: 10.1093/ageing/afaa144.). Age Ageing. 2020;

61. Hertzman C, Boyce T. How Experience Gets Under the Skin to Create Gradients in Developmental Health. Annu. Rev. Public Health. 2010;31(1):329-347.

62. Power C, Atherton K, Strachan D, et al. Life-course influences on health in British adults: effects of socio-economic position in childhood and adulthood. Int. J. Epidemiol. 2007;36(3):532-539.

63. Bush NR, Edgar RD, Park M, et al. The biological embedding of early-life socioeconomic status and family adversity in children's genome-wide DNA methylation. Epigenomics. 2018;10(11):1445-1461.

64. Danese A, Moffitt TE, Harrington $\mathrm{H}$, et al. Adverse childhood experiences and adult risk factors for age-related disease: depression, inflammation, and clustering of metabolic risk markers. Arch. Pediatr. Adolesc. Med.2009;163(12):1135-43.

65. Clegg A, Bates C, Young J, et al. Development and validation of an electronic frailty index using routine primary care electronic health record data. Age Ageing. 2016;45(3):353360.

66. Hood A, Waters T. Living standards, poverty and inequality in the UK: 2017-18 to 202122. 2017; Institute for Fiscal Studies. (https://www.ifs.org.uk/publications/10028). (Accessed January 1,2021)

67. Babor TF, Higgins-Biddle JC, Saunders JB, et al. The Alcohol Use Disorders Identification Test, Guidelines for Use in Primary Care, 2nd ed. Geneva, World Health Organization. 2001;(https://apps.who.int/iris/handle/10665/67205). (Accessed February 14, 2020) 
Table 1: Health deficits used to construct the 34-item Frailty Index at 50y in the 1958 British birth cohort, $2008(\mathrm{~N}=8711)$

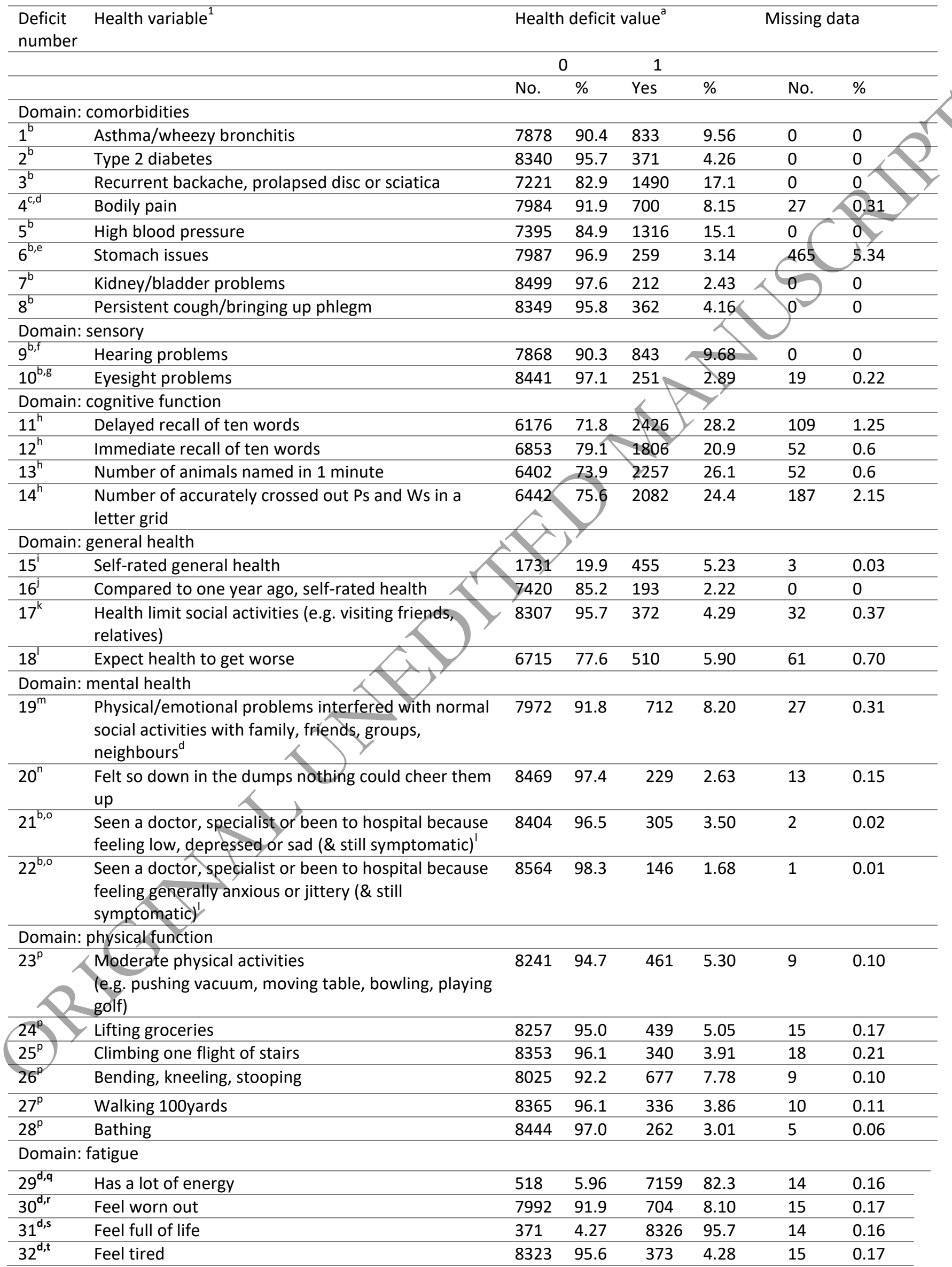




\begin{tabular}{llllllll}
\hline $33^{\mathrm{u}}$ & Time taken to usually fall asleep & 8152 & 93.8 & 543 & 6.24 & 16 & 0.18 \\
\hline $34^{\mathrm{d}, \mathrm{v}}$ & $\begin{array}{l}\text { Get enough sleep to feel rested upon waking in the } \\
\text { morning }\end{array}$ & 8097 & 93.0 & 610 & 7.01 & 4 & 0.05 \\
\hline
\end{tabular}

${ }^{a}$ All variables were self-reported and given a score of 1 (deficit present) or 0 (deficit absent). Deficits that included an intermediary response (e.g. sometimes or a little) were assigned a score between 0 and 1 as appropriate.

${ }^{\mathrm{b}} 0=\mathrm{No} ; 1=$ Yes

${ }^{\mathrm{c}} 0=$ none, very mild, mild, or moderate; $1=$ severe or very severe

${ }^{\mathrm{d}}$ Deficits expressed in last month

${ }^{\text {e}}$ Stomach issues include: gallstones, gastric ulcer, acid reflux, diverticulitis, hernia, tumour or cancer

${ }^{f}$ Hearing problems include: hearing loss in one or both ears, tinnitus, Menier's, age related degeneration, inability to hear certain noises;

${ }^{\mathrm{g}}$ Eyesight problems include: diabetes associated eye disease, glaucoma, cataract, macular degeneration, low vision or blind

${ }^{\mathrm{h}} 0=$ Upper 3 quartiles; 1 = Lowest quartile

${ }^{\mathrm{i}} 0=$ Excellent $\mathrm{n}=1731(19.9 \%) ; 0.25=$ Very $\operatorname{good} \mathrm{n}=2906(33.4 \%) ; 0.5=$ Good $\mathrm{n}=2544(29.2 \%) ; 0.75=$ fair $\mathrm{n}=1072(12.3 \%)$ and $1=$ Poor $\mathrm{n}=455(5.23 \%)$

${ }^{\mathrm{j}} 0=$ Much better/same $\mathrm{n}=7420(85.2 \%) ; 0.5=$ Worse $\mathrm{n}=1098(12.6 \%)$ and $1=$ Much worse $\mathrm{n}=193(2.22 \%)$

${ }^{\mathrm{k}} 0=\mathrm{A}$ good bit/some/a little/none of the time $\mathrm{n}=8307(95.7 \%) ; 1=$ All/most of the time $\mathrm{n}=372(4.29 \%)$

${ }^{1} 0=$ Don't know/mostly false/definitely false $\mathrm{n}=6715(77.6 \%) ; 0.5=$ Mostly true $\mathrm{n}=1425(16.5 \%) ; 1=$ Definitely true $\mathrm{n}=510(5.90 \%)$

${ }^{\mathrm{m}} 0=$ Not at all/slightly/moderately $\mathrm{n}=7972(91.8 \%) ; 1=$ Quite a bit/extremely $\mathrm{n}=712(8.20 \%)$

${ }^{\mathrm{n}} 0=\mathrm{A}$ good $\mathrm{bit} / \mathrm{some} / \mathrm{a}$ little/none of the time $\mathrm{n}=8469(97.4 \%) ; \mathrm{All} / \mathrm{most}$ of the time $\mathrm{n}=229(2.63 \%)$

${ }^{\circ} 0=$ In the last four years and still symptomatic most of the time

${ }^{\mathrm{P}} 0=$ Limited a little/not limited; 1 =Limited a lot

${ }^{\mathrm{q}} 0=\mathrm{All} /$ some of the time $\mathrm{n}=7159(82.3 \%) ; 0.5=$ A little of the time $\mathrm{n}=1020(11.7 \%) ; 1=$ None of the time $\mathrm{n}=518(5.96 \%)$

${ }^{\mathrm{r}} 0=\mathrm{A}$ good bit of the time/some of the time/a little of the time/none of the time $\mathrm{n}=7992(91.9 \%)$ and $1=$ All/most of the time $\mathrm{n}=704(8.10 \%)$

${ }^{\mathrm{s}} 0=\mathrm{All} / \mathrm{most}$ of the time/a good bit of the time/some of the time/a little of the time $\mathrm{n}=8326(95.7) ; 1=$ None of the time $371(4.27 \%)$.

${ }^{\mathrm{t}} 0=\mathrm{A}$ good bit of the time/some of the time/a little of the time/none of the time $\mathrm{n}=8323(95.6) ; 1=$ All $/ \mathrm{most}$ of the time $\mathrm{n}=373(4.28 \%)$

${ }^{u} 0=1$ hour or less $\mathrm{n}=8152(93.8) ; 1=$ over 1 hour $\mathrm{n}=543(6.24 \%)$

${ }^{\mathrm{v}} 0=$ All/most/a good bit/some/a little bit of the time $\mathrm{n}=8097(93.0 \%) ; 1=$ None of the time $(1): 610(7.01 \%)$ 
Table 2: Characteristics of the 1958 British birth cohort, $1958-2008(\mathrm{~N}=8711)^{\mathrm{a}}$

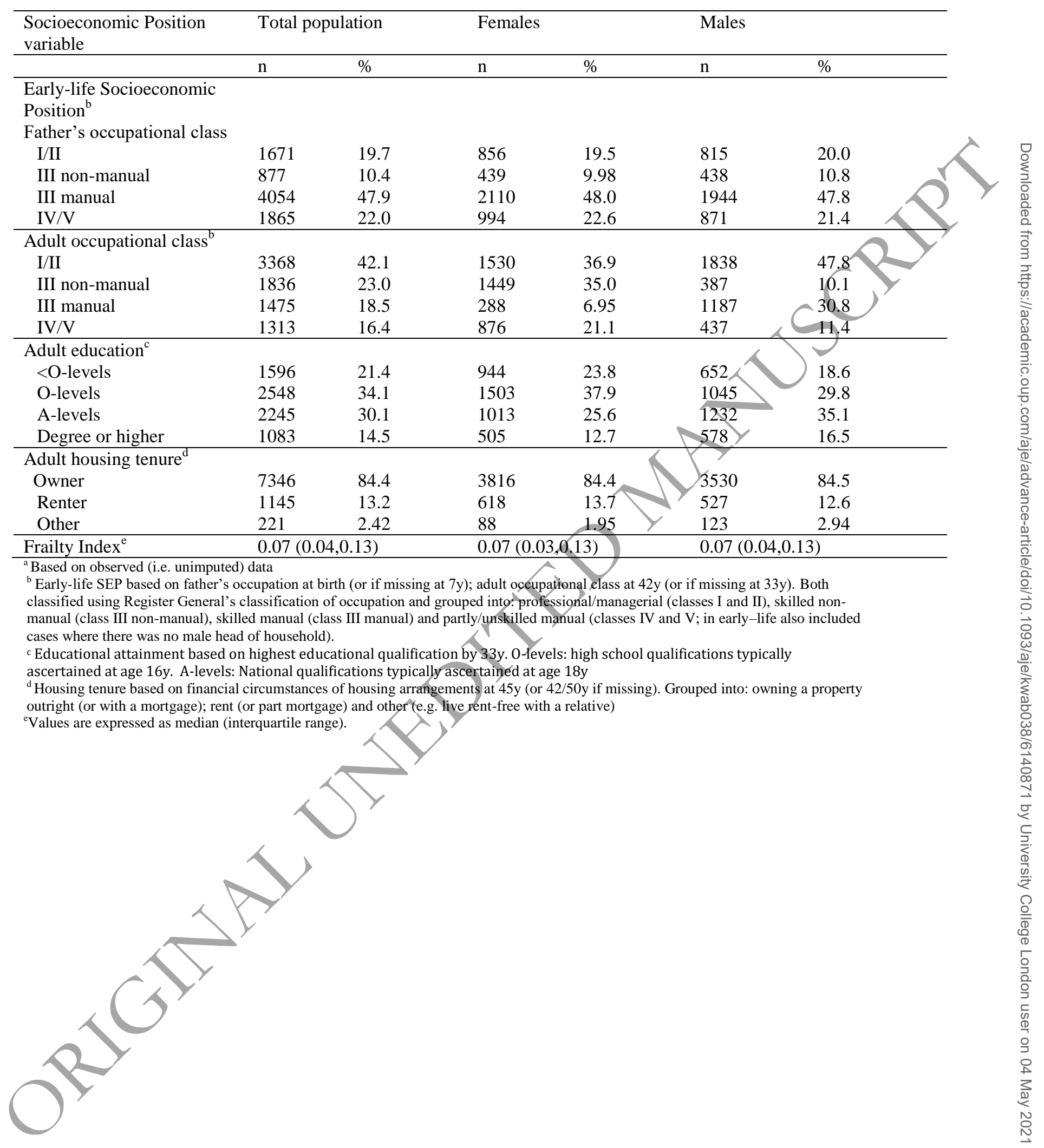


Table 3: Total, natural direct and natural indirect effects (mean percentage difference, $95 \%$ confidence intervals) and proportion mediated $^{\mathrm{a}}$, of the frailty index at $50 \mathrm{y}$ by socioeconomic position at birth (mediator: adult socioeconomic position) ${ }^{\mathrm{b}}$

\begin{tabular}{|c|c|c|c|c|c|c|}
\hline \multirow{2}{*}{$\begin{array}{l}\text { Socioeconomic position at } \\
\text { birth } \\
\text { (baseline: } \mathrm{I} / \mathrm{II})\end{array}$} & \multicolumn{2}{|c|}{ III non-manual } & \multicolumn{2}{|c|}{ III manual } & \multicolumn{2}{|c|}{ IV/V } \\
\hline & $\begin{array}{l}\text { Mean \% } \\
\text { difference }\end{array}$ & $95 \% \mathrm{CI}$ & $\begin{array}{c}\text { Mean \% } \\
\text { difference }\end{array}$ & $95 \% \mathrm{CI}$ & $\begin{array}{l}\text { Mean \% } \\
\text { difference }\end{array}$ & $95 \% \mathrm{CI}$ \\
\hline Total effect & 10.3 & $3.02,17.7$ & 27.8 & $22.2,33.3$ & 42.0 & \\
\hline $\begin{array}{l}\text { Natural direct effect } \\
\text { (not via adult socioeconomic } \\
\text { position) }\end{array}$ & 15.3 & $7.88,22.7$ & 32.4 & $26.6,38.1$ & 23.0 & \\
\hline $\begin{array}{l}\text { Natural indirect effect } \\
\text { (via adult socioeconomic } \\
\text { position) }\end{array}$ & -4.94 & $\begin{array}{l}-7.77,- \\
2.10\end{array}$ & -4.61 & $\begin{array}{l}-7.28,- \\
1.95\end{array}$ & & $\begin{array}{l}15.5, \\
22.4\end{array}$ \\
\hline $\begin{array}{l}\text { Proportion mediated }{ }^{\mathrm{a}} \\
\text { (via adult socioeconomic } \\
\text { position) }\end{array}$ & -0.48 & $\begin{array}{l}-20.4 \\
19.4\end{array}$ & -0.17 & $\begin{array}{l}-0.28, \\
0.06\end{array}$ & & $\begin{array}{l}0.35 \\
0.55\end{array}$ \\
\hline
\end{tabular}

aproportion mediated is the natural indirect effect divided by the total effect

${ }^{\mathrm{b}}$ Analysis adjusted for sex and adult physical activity, smoking and problem drinking as confounders of the adult socioeconomic position-frailty relationship that are themselves influenced by early-life socioeconomic position (see text, Figure 1 and Web appendix 1 for details) 
Figure 1: Proposed relationship between early-life SEP, adult SEP and frailty. Boxes represent observed variables. The circle is a latent variable. See methods section for details.

Figure 2: ex-adjusted Kaplan Meier survival probabilities stratified by frailty fifths in the 1958 birth cohort, 2008-2016 (n=8711, 209 deaths). Higher FI scores represent higher levels of frailty. 


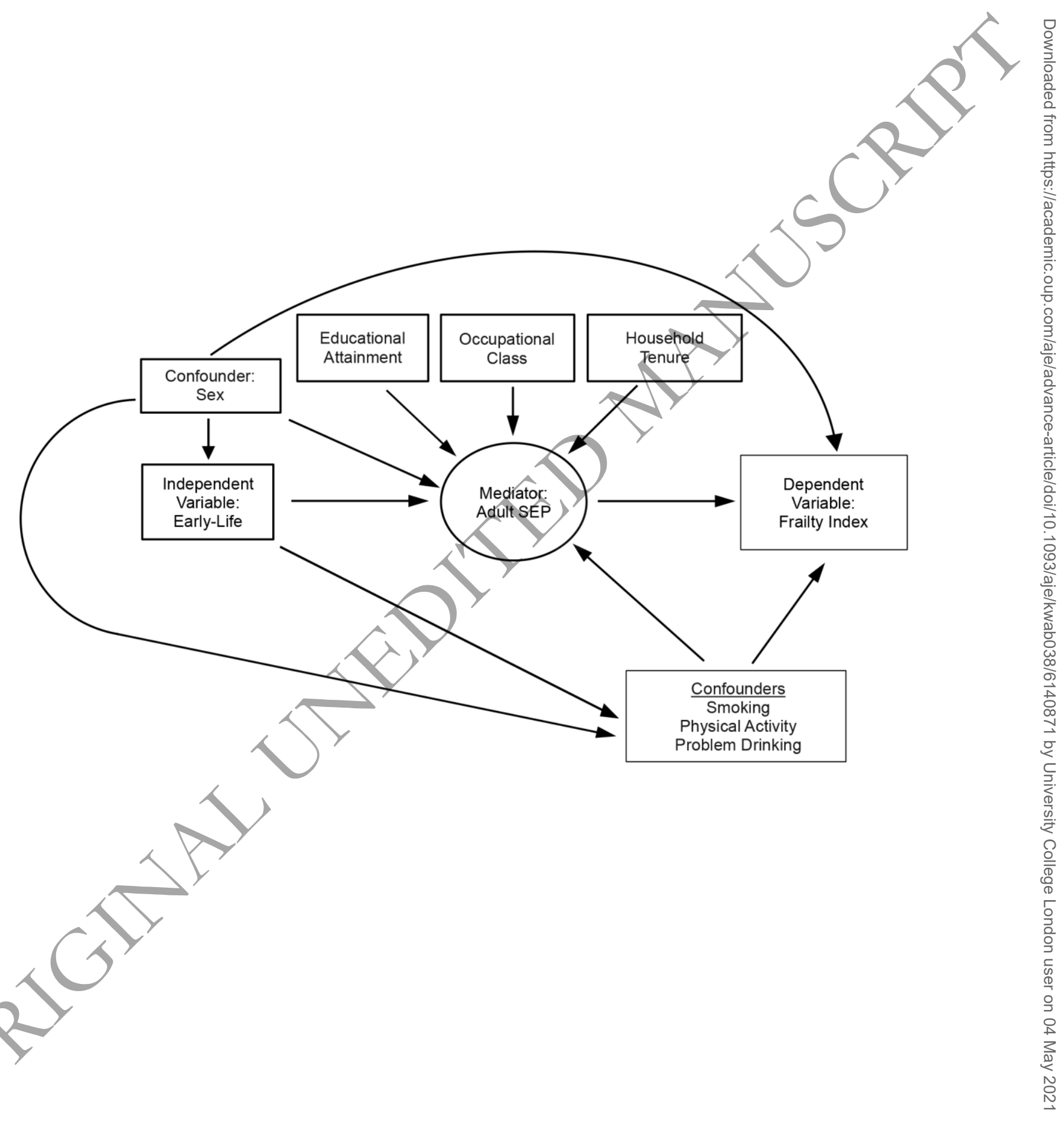




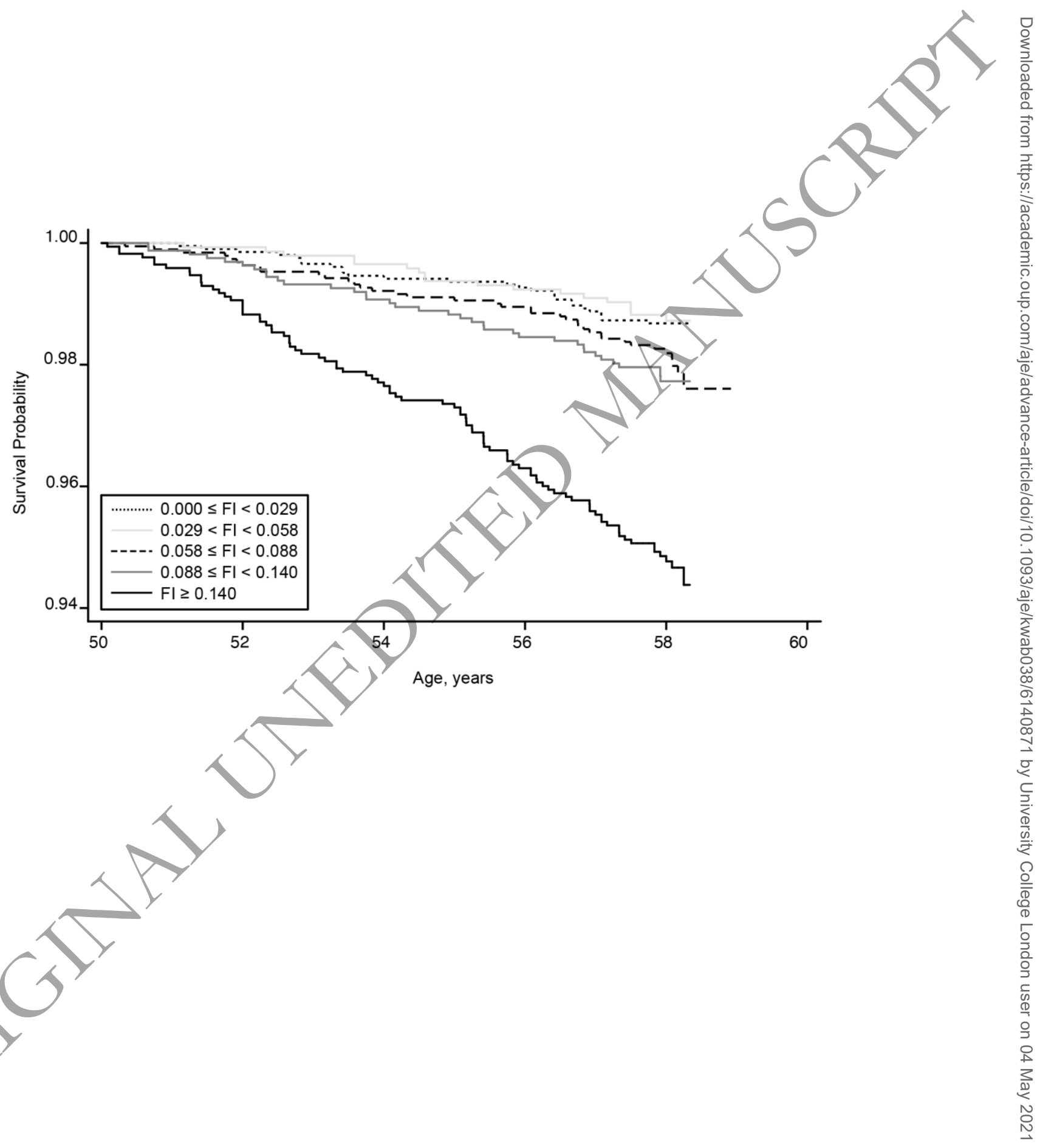

